\title{
The Role of Rice Hull Liquid Smoke in the Traumatic Ulcer Healing
}

\author{
Ira Arundina ${ }^{1}$ Indeswati Diyatri ${ }^{1}$ Tuti Kusumaningsih ${ }^{1}$ Meircurius Dwi Condro Surboyo ${ }^{2}$ Elita Monica ${ }^{3}$ \\ Novitasari Mira Afanda ${ }^{3}$
}

\author{
${ }^{1}$ Department of Oral Biology, Faculty of Dental Medicine, \\ Universitas Airlangga, Surabaya, Indonesia \\ ${ }^{2}$ Department of Oral Medicine, Faculty of Dental Medicine, \\ Universitas Airlangga, Surabaya, Indonesia \\ ${ }^{3}$ Undergraduate Student, Faculty of Dental Medicine, Universitas \\ Airlangga, Surabaya, Indonesia
}

Address for correspondence Dr. Ira Arundina, drg., M.Si, Department of Oral Biology, Faculty of Dental Medicine, Universitas Airlangga, Jln. Prof. Dr. Moestopo 47, Surabaya 60132, Indonesia (e-mail: arundinafkg@yahoo.com).

Eur J Dent:2021;5:33-38

\begin{abstract}
Keywords

- traumatic ulcer

- fibroblast

- macrophage

- lymphocyte

- rice hull

- liquid smoke

- IL-6 and TGF- $\beta$

Objective The aim of this study was to prove the role of rice hull liquid smoke (RH-LS) on lymphocytes, macrophages, fibroblasts, interleukin 6 (IL-6), and transforming growth factor $\beta$ (TGF- $\beta$ ) expression during traumatic ulcer healing.

Materials and Methods The RH-LS was obtained from the pyrolysis process. Traumatic ulcers were made $10 \mathrm{~mm}$ along the labial fornix incisive inferior of Wistar rat using a round stainless-steel blade. In control group, traumatic ulcers were treated using sterile water, and meanwhile in experimental group were treated using RH-LS once a day for 3, 5, and 7 days. After treatment, animal was terminated and their labial fornix incisive inferior tissues were biopsy and stained using hematoxylin and eosin staining to determine lymphocytes, macrophages, and fibroblasts. The IL- 6 and TGF- $\beta$ expressions were analyzed used immunohistochemistry staining.

Result The lymphocytes, macrophages, and fibroblasts were higher in the RH-LS group for 3-, 5-, and 7-day treatment $(p<0.05)$. The IL-6 expression was higher only in the 5-day treatment, and the TGF- $\beta$ expression was higher in the 3 - and 7 -day treatment. Conclusion The RH-LS able to accelerated the traumatic ulcer healing by increasing the number of lymphocytes, macrophages, fibroblasts, IL-6, and TGF- $\beta$ expression.
\end{abstract}

\section{Introduction}

Traumatic ulcer is a common lesion in the oral cavity, around $83.6 \%$ of people have ever experienced it. ${ }^{1}$ The prevalence of traumatic ulcers varies around 3 to $24 \%$ worldwide. ${ }^{2}$ Ulcer is characterized by loss of the epithelium, causing a chief complaint of pain., ${ }^{3,4}$ The current topical treatment of traumatic ulcers, such as benzydamine hydrochloride in some special cases like in the diabetic condition, does not promote healing ${ }^{5}$ that is why an alternative treatment is needed.

The carbonization of wood at high temperature and without oxygen produces liquid smoke, then the smoke is condensed at a room temperature, and this whole of this

DOI https://doi.org/ 10.1055/s-0040-1714445 ISSN 1305-7456. process is called pyrolysis. ${ }^{6,7}$ Liquid smoke compositions are obtained from the degradation of wood components through pyrolysis. ${ }^{7,8}$ The degradation of lignin generates phenolic compounds that have several beneficial effects in wound healing including traumatic ulcer., ${ }^{5,8}$

Rice (Oryza sativa $L$ ) is the staple food for people all around the world, especially in Asia including Indonesia. ${ }^{9}$ Postharvesting rice process produces $20 \%$ rice hull as its byproduct, ${ }^{9}$ and rice hull can be processed through pyrolysis to become rice hull liquid smoke (RH-LS). RH-LS contains phenolic compounds, such as guaiacol, 2,6-dimethoxyphenols, phenol, and 4-ethyl-2-methoxyphenol (2-EMP) have antioxidant effect which bind to reactive oxygen species (ROS), inhibit the production of

\section{(c) 2020. European Journal of Dentistry.}

This is an open access article published by Thieme under the terms of the Creative Commons Attribution-NonDerivative-NonCommercial-License, permitting copying and reproduction so long as the original work is given appropriate credit. Contents may not be used for commercial purposes, or adapted, remixed, transformed or built upon. (https://creativecommons.org/licenses/by-nc-nd/4.0/)

Thieme Medical and Scientific Publishers Pvt. Ltd., A-12, 2nd Floor, Sector 2, Noida-201301 UP, India 
pro-inflammatory cytokines, and inhibit the activation of nuclear factor kappa $\beta$ (NF-кB). ${ }^{9-11}$ The inhibition of NF-кB makes the polarization of anti-inflammatory macrophage (M2) more dominant compared with the pro-inflammatory macrophage (M1). ${ }^{12} \mathrm{M} 2$ with the help of lymphocyte secrete growth factors, such as fibroblast growth factor-2 (FGF-2), transforming growth factor $\beta$ (TGF- $\beta$ ), and chemokine ligand-18 (CCL-18). Those growth factors accelerate the proliferation of fibroblast and collagen which are needed in the healing process. ${ }^{9,13-17}$

Despite all the promising finding in the literatures mentioned above, RH-LS has a promising potential as treatment to accelerate the traumatic ulcer healing. Therefore, an in vivo research on the effect of RH-LS using macrophage, lymphocytes, fibroblast, IL- 6 , and TGF- $\beta$ expressions as the indicators of the healing of traumatic ulcer needs to be conducted.

\section{Materials and Methods}

\section{Pyrolysis and Distillation of Liquid Smoke}

The rice hull (Oryza sativa $L$ ) were collected at the Center of Rice Processing in Tumpang village. The pyrolysis process was conducted in the Research and Development of Forest Products Laboratory, Bogor, Indonesia (ISO number 17025:2008). First of all, total 1,760 $\mathrm{g}$ of rice hull were airdried at room temperature.

A kerosene pump stove was used as the heater of the pyrolysis furnace, as well as $30 \mathrm{~cm}$ in diameter and $40 \mathrm{~cm}$ in height encircling reactor was used. The reactor is connected to the cooling tubes by pipeline for condensing the fumes and generating the liquid smoke. The air-dried rice hull was put inside the furnace and then the furnace was closed. After that, the setting of the condenser was done, and cold water was used to stream the cooling tube. At a temperature of $400^{\circ} \mathrm{C}$, the pyrolysis was performed for 4.5 hours with a heating rate of $3.33^{\circ} \mathrm{C} .{ }^{18}$ The formula below was used to calculate the yield of the liquid smoke $(\%)^{18}$ :

$$
\text { yield }(\%)=\frac{\text { liquid smoke }(g)}{\text { rice hull }(g)} \times 100
$$

The liquid smoke was then stored for 48 hours and after that the filtration process using Whatman 52 (Whatman 52, Cat No 1452, GE Healthcare Life Science, Singapore) was done. After that, a distillation process at the temperature of 120 to $150^{\circ} \mathrm{C}$ was done to purificate the liquid smoke. ${ }^{19}$ The yield of distilled liquid smoke derived from rice hull (\%) was calculated using the following formula ${ }^{18}$ :

$$
\text { liquid smoke }(\%)=\frac{\text { condensed liquid smoke }(m l)}{\text { liquid smoke }(m l)} \times 100
$$

\section{Animals}

Ethics approval was obtained from the Ethical Clearance of Health Experiment Committee, Faculty of Dental Medicine, Airlangga University, Surabaya under registered-number 132/HRECC.FODM/IV/2019.
This research was comprised of 2-month-old 30 male Wistar rats with a weight range of 120 to $160 \mathrm{~g}$. Animal Testing Laboratory, Department of Biochemistry, Faculty of Medicine, Airlangga University, Surabaya was chosen as the place where the treatment and experiment of animals were done. Collective cages equipped with artificial light with a cycle of 12 hours light/12 hours dark at room temperature $\left(27^{\circ} \mathrm{C}\right)$ were used to house Wistar rat in which free access of water and standard diet were given.

\section{Traumatic Ulcer Induction}

Wistar rats were put under anesthesia using a ketamine/ xylazine cocktail, after that, at the labial fornix incisive inferior a $10 \mathrm{~mm}$-long incision were made using a round stainless steel blade to induce traumatic ulcers. ${ }^{20}$ They were confirmed if a yellowish-white ulcer with an erythematous halo appear after 24 hours. ${ }^{5}$

Wistar rats were randomly assigned to a control group, and an experimental group after the traumatic ulcers were confirmed. The intraoral dropping method was used for the topical treatment of RH-LS and sterile water. In the control group, the traumatic ulcers were treated topically using sterile water; meanwhile, in the experimental group, they were treated topically using RH-LS with a dosage of $20 \mu \mathrm{L} / 20$ gr once a day for 3,5 , and 7 days. ${ }^{18}$

\section{Fibroblast, Macrophage, and Lymphocyte Counting on Traumatic Ulcer}

After being treated for 3, 5, and 7 days in each group, the rats were terminated and their labial fornix incisive inferior tissues were subjected to biopsy before a hematoxylin and eosin staining to determine the number of fibroblasts, macrophages, and lymphocytes. While the TGF- $\beta$ (TGF- $\beta$ mouse monoclonal, Santacruz biotechnology) and IL-6 (IL-6 mouse monoclonal, Santacruz biotechnology) expression was analyzed using immunohistochemistry. All measurement was done using light microscope (Nikon H600L microscope; Nikon, Japan) with a magnification of $\times 400$ at five fields of view with single blind operator.

\section{Statistical Analysis}

The data were shown in the form of mean \pm standard deviation $(X \pm S D)$ for each group and each measurement. Then, the data were analyzed using independent $t$-test and the significance was set at $p<0.05$.

\section{Result}

\section{Pyrolysis and Distillation of Liquid Smoke}

The pyrolysis process of 1,760 $\mathrm{g}$ rice hull was performed with the final temperature $400^{\circ} \mathrm{C}$ for 4.5 hours and then the liquid smoke was distilled at 120 to $150^{\circ} \mathrm{C}$ (-Table $\mathbf{1}$ ).

Table 1 The yield of pyrolysis and distillation of liquid smoke

\begin{tabular}{|l|l|}
\hline Component & $\%$ \\
\hline Liquid smoke & 34.82 \\
\hline distilled & 87 \\
\hline
\end{tabular}


The Number of Macrophages on Traumatic Ulcer

The histopathology of traumatic ulcer after topical treatment of RH-LS can be seen in - Fig. 1. The number of macrophages after topical treatment of RH-LS for 3 days was higher than control $(7.20 \pm 0.84 ; p=0.005)$. The topical treatment of RH-LS for 5 and 7 days was higher than control ( $p=0.004$ and $p=0.022$, respectively; - Fig. $2 \mathrm{~A}$ ).

\section{The Number of Lymphocytes on Traumatic Ulcer}

The number of lymphocytes after topical treatment of RH-LS for 3 and 5 days was higher than control $(p=0.001$ and $p=0.000$, respectively), but there is no difference in the treatment for 7 days $(p=0.108$; - Fig. 2 B $)$.

\section{The Number of Fibroblasts on Traumatic Ulcer}

The number of fibroblasts after topical treatment of RH-LS for 3,5 , and 7 days was higher than control $(p=0.032, p=0.001$, and $p=0.025$, respectively; - Fig. 2 C).

\section{The Interleukin-6 Expression on Traumatic Ulcer}

The IL-6 expression after topical treatment of RH-LS for 5 days was higher than control $(p=0.001)$. The topical treatment of RH-LS for 3 and 7 days showed no differences with control

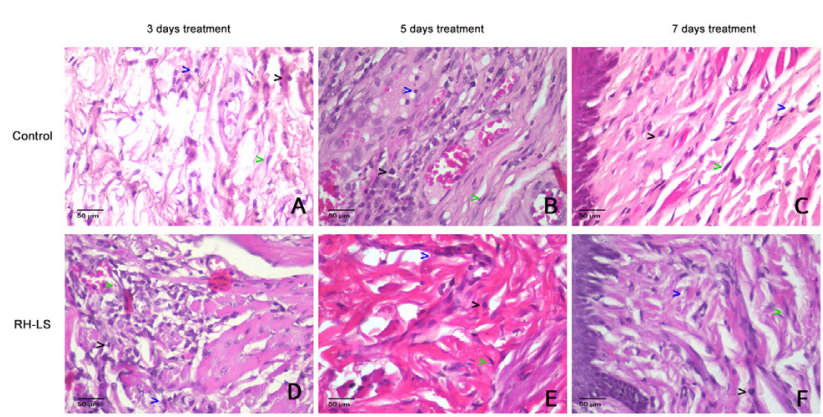

Fig. 1 The histopathology of traumatic ulcer tissue. The lymphocytes (blue arrow), macrophages (black arrow), and fibroblasts (green arrow) cells were analyzed using Hematoxylin and Eosin staining. Magnification at $\times 400$. groups $(p=0.088$ and $p=0.293$, respectively; - Fig. 3 and -Fig. 4A).

\section{The Transforming Growth Factor- $\beta$ Expression on Traumatic Ulcer}

The TGF- $\beta$ expression after topical treatment of RH-LS for 3 and 7 days was higher than control $(p=0.034$ and $p=0.019$, respectively). The topical treatment of RH-LS for 5 days showed no differences with control groups $(p=0.059$; -Fig. 5 and -Fig. 4B).

\section{Discussion}

RH-LS is a liquid smoke that produced from rice hull through the pyrolysis process. The process of pyrolysis includes different response forms to be specific decomposition, polymerization, oxidation, and condensation. The reactions that occur during pyrolysis are the decomposition of structures such as cellulose, hemicellulose, and lignin. In the pyrolysis process,

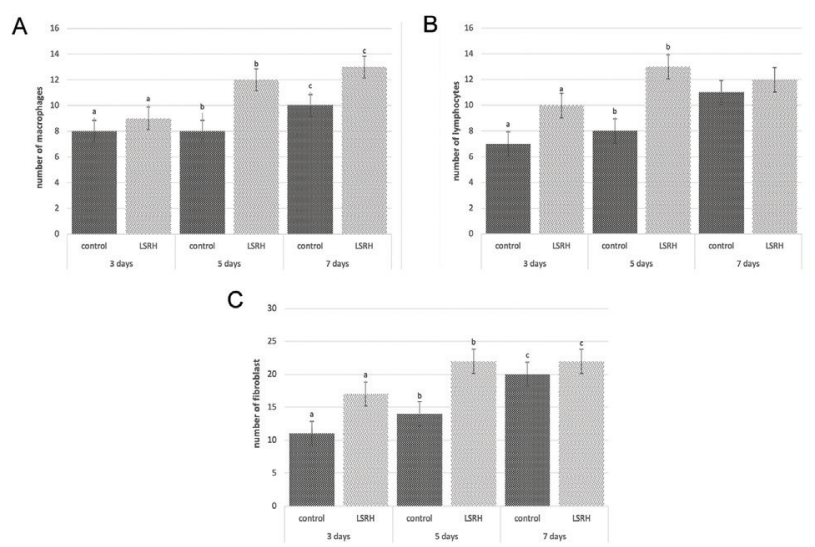

Fig. 2 The number of lymphocytes (A), macrophages (B), and fibroblasts $(\mathbf{C})$. The same character on the top of column, indicated different each group ( $t$-test: $p<0.05)$. The interleukin-6 expression on traumatic ulcer.
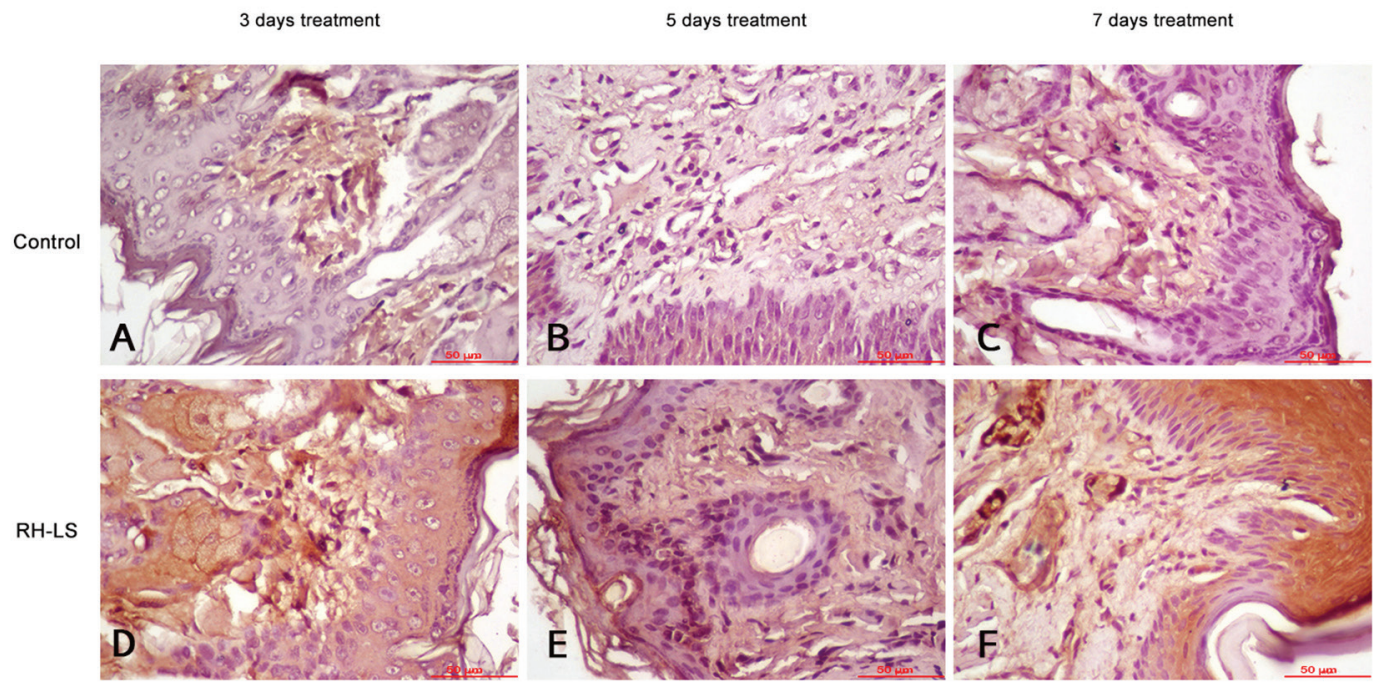

Fig. 3 The interleukin- 6 expression on traumatic ulcer tissue with immunohistochemistry staining. Magnification at $\times 400$. 
compounds are formed such as carbonyl, acids, and phenols. In addition, it also produces carcinogenic compounds such as polycyclic aromatic hydrocarbons (PAHs). PAHs are formed naturally resulting from incomplete combustion, and this compound is formed at pyrolysis temperatures ranging from 500 to $900^{\circ} \mathrm{C}$. PAH formation rate is also influenced by the source. Some PAH compounds such as benzo(a)pyrene ${ }^{21}$ is a carcinogenic substance and can cause damage to amino acids and vitamins..$^{22}$ One way to separate and eliminate unwanted components such as benzo(a)pyrene is by purification. One of the purifications methods is distillation to remove that compound. ${ }^{23}$

$\mathrm{RH}-\mathrm{LS}$ in this study was made with a pyrolysis temperature of $400^{\circ} \mathrm{C}$ because the products can be produced optimally at temperature of 400 to $550^{\circ} \mathrm{C}$. Temperature $400^{\circ} \mathrm{C}$ produced more phenol, ferulic acid, and guaiacol than the temperature of $800^{\circ} \mathrm{C} .^{24}$

The treatment of RH-LS to the traumatic ulcer showed a higher number of lymphocytes, macrophages, fibroblasts for 3, 5, and 7 days. Phenolic compounds which are contained in RH-LS, such as EMP and guaiacol, might have the role to increase them. EMP and guaiacol has antioxidant abilities that can increase proliferation lymphocytes, macrophages, and fibroblasts. The antioxidant ability is related to ability of inhibit the formation of ROS. Elevated ROS will cause oxidative stress in lymphocytes leading them to apoptosis; hence, with the inhibition of ROS, the number of lymphocytes will
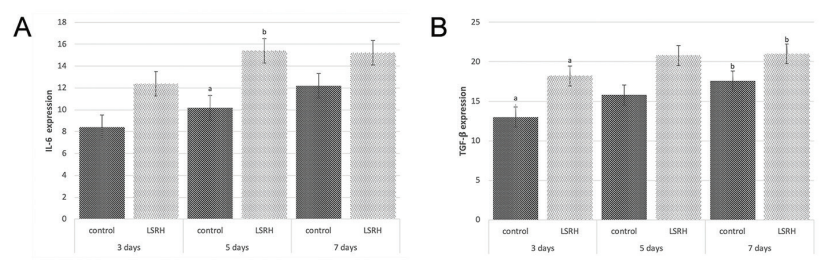

Fig. 4 The interleukin-6 expression (A) and transforming growth factor- $\beta$ expression (B). The same character on the top of column, indicated different each group ( $t$-test: $p<0.05)$. be increased. ${ }^{25}$ Lymphocytes play a role in releasing lymphokines, epidermal growth factor, basic fibroblast growth factor, ${ }^{26}$ that influence the recruitment of macrophages to the wound and in the end promote the fibroblast proliferation. ${ }^{27}$

The phenolic compound in RH-LS able to interfere the ІкB kinase (IKK) and NF-кB signaling pathway by inhibiting the ROS and resulting inhibition of cytokines production, such as tumor necrosis factor (TNF)- $\alpha$, IL-6, and IL-1 $1{ }^{28}$ The previous research has proved that RH-LS can reduce the pro-inflammatory cytokine, the TNF- $\alpha$, by inhibiting the activation of NF-KB through the inhibition of IKK activity. ${ }^{29}$ Other research with liquid smoke from coconut shell also confirmed that liquid smoke able to decrease the NF-KB and TNF- $\alpha$ expression. ${ }^{18}$ The result of this study is different with two previous studies. The pro-inflammatory cytokines, IL-6 expression, is higher in the treatment of RH-LS for 5-day treatment. Even the IL-6 is pro-inflammatory cytokines, its need in the traumatic ulcer healing. ${ }^{30}$ IL- 6 is released by M2 macrophages along with growth factors, such as TGF- $\beta$, platelet-derived growth factor, and basic fibroblast growth factor, which is the higher TGF- $\beta$ expression also observed after treated with RH-LS for 3-day and 5-day treatment. That IL- 6 and TGF- $\beta$ have contributed in the fibroblast proliferation and collagen production. ${ }^{15,17}$ The increase of IL-6 expression promoted the fibroblasts proliferation and extracellular matrix production, including procollagen and fibronectin. ${ }^{31}$ This higher IL-6 and TGF- $\beta$ expression in this study strengthen the previous study that liquid smoke able increased the fibroblast, ${ }^{32}$ and collagen formation in oral ulcer healing. ${ }^{5}$ The higher level of IL-6 and TGF- $\beta$ can accelerate wound closure, granulation tissue formation, neovascularization, and re-epithelialization. ${ }^{33,34}$

The number of macrophages and lymphocytes is significant increased during treatment with RH-LS in this research. The bidirectional interaction between lymphocytes and macrophages is well established, and the polarization paradigm of macrophages is derived from their interaction with lymphocytes. Recruitment of macrophages plays a important
3 days treatment

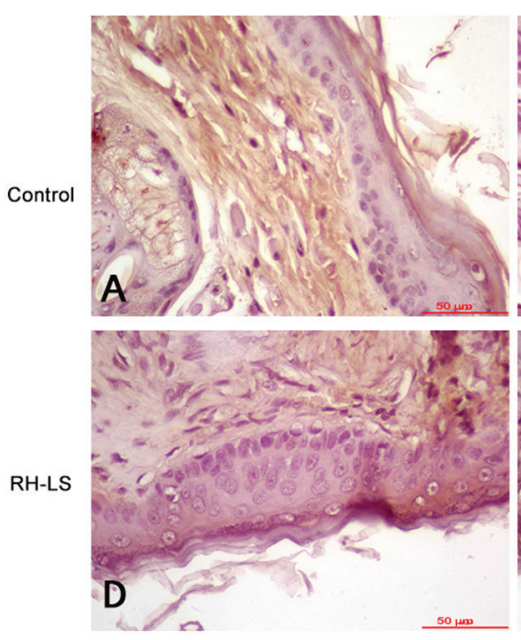

5 days treatment
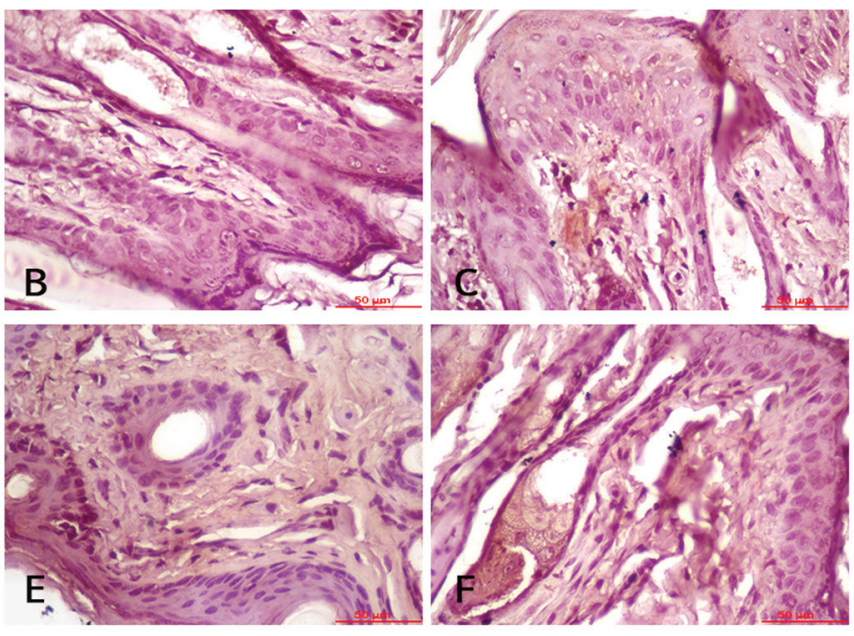

Fig. 5 Transforming growth factor- $\beta$ expression on traumatic ulcer tissue with immunohistochemistry staining. Magnification at $\times 400$. 
role in healing process of traumatic ulcers. ${ }^{35}$ Macrophages play a role in the wound healing process of M1 polarization in the initial stages of wound healing and the properties of M2 polarization expression during the later stages of wound healing. M1 macrophages mediate tissue damage and have a proinflammatory effect, while $\mathrm{M} 2$ macrophages function in cleansing debris, induction of angiogenesis, and tissue remodeling. ${ }^{36}$ The inhibition of NF-KB results a switch from M1 polarization to M2 polarization. This condition make the M2 becomes more dominant, for produce the anti-inflammatory cytokine. ${ }^{36}$

The dominant M2 polarization results in the more abundant release of anti-inflammatory cytokines and growth factors, one of them is TGF- $\beta$ which is proved to be increased after the application of RH-LS. In every phase of wound healing, TGF- $\beta$ takes an important role to suppress the inflammatory response and to promote the formation of granulation tissue, ${ }^{37,38}$ promoting fibroblast migration and promoting wound healing. ${ }^{39,40}$ In the current study, it was found that RH-LS increased the TGF- $\beta$ expression. The increase of TGF- $\beta 1$ promoted the fibroblast proliferation which can be seen in this study that there was an increase of fibroblast after RH-LS topical application. The ability to increase fibroblast of TGF- $\beta$ plays an important role to accelerate wound healing. On the 5-daytreatment, TGF- $\beta$ expression found not significant compared with the control. TGF- $\beta$ secretion starts in the early proliferative phase, then the secretion keeps on going, and reaches its peak on the 7 day. ${ }^{41,42}$ That is why the significant differences were found on the 3 days and the 7 days after RH-LS treatment.

Based on the results of the study, there was a significant difference between the number of macrophages in the RH-LS treatment. This is due to the ability of RH-LS in inhibiting the production of ROS and inhibiting the production of pro-inflammatory cytokines such as TNF- $\alpha$ to accelerating the inflammatory phase. ${ }^{43}$ The inhibition of ROS production resulted in the inhibition of NF-KB which later resulted in a switch from M1 polarization to M2 polarization and makes M2 more dominant. The dominant M2 increases IL-6, TGF- $\beta 1$, PDGF, FGF-2, and IL-10 secretion. It can be seen in this study that IL-6 and TGF- $\beta 1$ increased after RH-LS treatment, which later contributes in wound healing by increasing the fibroblast. From the mechanism that is explained above, topical application of RH-LS to traumatic ulcer can increase the infiltration of lymphocytes, macrophages, increase TGF- $\beta 1$, and IL-6 expression and later increase the fibroblasts. This condition accelerates the inflammatory phase and indicates a faster traumatic ulcer healing.

\section{Conclusion}

The topical application of RH-LS increased the infiltration of macrophages, lymphocytes, IL-6, and TGF- $\beta$ expression and resulted in the increase of fibroblasts number in traumatic ulcer. Therefore, it accelerated the healing of traumatic ulcer.

\section{Funding}

This work was supported by Ministry of Higher Education 2020 with grant number 607/UN3.14/PT/2020.

\section{Conflict of Interest}

None declared.

\section{References}

1 Puspitasari D, Apriasari ML. Analysis of traumatic ulcer healing time under the treatment of the Mauli banana (Musa acuminata) 25\% stem extract gel. Padjadjaran J Dent 2017;29(1):21-25

2 Apriasari ML, Rahayu RP, Ernawati D. Mauli banana stem extract application increased expression of NF- $\mathrm{kB}$ in traumatic ulcer healing. Research 2018;67(32):67-70

3 Mortazavi H, Safi Y, Baharvand M, Rahmani S. Diagnostic features of common oral ulcerative lesions: an updated decision tree. Int J Dent 2016;2016:7278925

4 Ali SA, Saudi HI. An expert system for the diagnosis and management of oral ulcers ScienceDirect: an expert system for the diagnosis and management of oral ulcers. Tanta Dent J 2015;11(1):42-46

5 Surboyo MDC, Arundina I, Rahayu RP. Increase of collagen in diabetes-related traumatic ulcers after the application of liquid smoke coconut shell. Dent J 2017;71(32):71-75 (Majalah Kedokt Gigi)

6 Oramahi HA, Diba F. Maximizing the production of liquid smoke from bark of durio by studying its potential compounds. Procedia Environ Sci 2013;17:60-69

7 Wagiman FX, Ardiansyah A. Witjaksono. Activity of coconut-shell liquid-smoke as an insecticide on the rice brown planthopper (Nilaparvata lugens) J Agric Biol Sci 2014;9(9): 293-296

8 Ramakrishnan S, Moeller P. Liquid smoke. Product Hardwood Pyrolysis 2002;47(1):366-367

9 Kim SP, Yang JY, Kang MY, Park JC, Nam SH, Friedman M. Composition of liquid rice hull smoke and anti-inflammatory effects in mice. J Agric Food Chem 2011;59(9):4570-4581

10 Hayden MS, Ghosh S, Regulation of NF- K B by TNF family cytokines. Vol. 26, Seminars in Immunology. Elsevier Ltd; 2014;253-266

11 Lingappan K. NF-KB in Oxidative Stress. Curr Opin Toxicol 2018;7:81-86

12 Zhou Y, Zhang T, Wang X, et al. Curcumin modulates macrophage polarization through the inhibition of the tolllike receptor 4 expression and its signaling pathways. Cell Physiol Biochem 2015;36(2):631-641

13 Townsend CM, Beauchamp RD, Evers BM, Mattox KL, Sabiston Textbook of Surgery: The Biological Basis of Modern Surgical Practice. Shock. 20th edition. Elsevier Ltd; 2001;15(5):408

14 Chistiakov DA, Myasoedova VA, Revin VV, Orekhov AN, Bobryshev YV. The impact of interferon-regulatory factors to macrophage differentiation and polarization into M1 and M2. Immunobiology 2018;223(1):101-111

15 Ploeger DT, Hosper NA, Schipper M, Koerts JA, de Rond S, Bank RA. Cell plasticity in wound healing: paracrine factors of M1/ M2 polarized macrophages influence the phenotypical state of dermal fibroblasts. Cell Commun Signal 2013;11(1):29

16 Akiyama M, Yasuoka H, Yoshimoto K, Takeuchi T. CC-chemokine ligand 18 is a useful biomarker associated with disease activity in IgG4-related disease. Ann Rheum Dis 2018;77(9): 1386-1387 
17 Bi Y, Chen J, Hu F, Liu J, Li M, Zhao L. M2 Macrophages as a potential target for antiatherosclerosis treatment. Neural Plast 2019;2019:6724903 doi:10.1155/2019/6724903

18 Surboyo MDC, Arundina I, Rahayu RP, Mansur D, Bramantoro T. Potential of Distilled Liquid Smoke Derived from Coconut (Cocos nucifera L) Shell for Traumatic Ulcer Healing in Diabetic Rats. Eur J Dent 2019;13(2):271-279

19 Desniorita M. The effect of adding liquid smoke powder to shelf life of sauce. Int J Adv Sci Eng Inf Technol 2015;5(6):457-459

20 Surboyo MDC, Ernawati DS, Arundina I, Rahayu RP. Oral ulcer healing after treatment with distilled liquid smoke of coconut shell on diabetic rats. J Krishna Inst Med Sci Univ 2019;8(2):70-79

21 Lingbeck JM, Cordero P, O’Bryan CA, Johnson MG, Ricke SC, Crandall PG. Functionality of liquid smoke as an all-natural antimicrobial in food preservation. Meat Sci 2014;97(2):197-206

22 Anggraini SPA, Yuniningsih S. Liquid smoke purification process for benzo (A) pyrene levels lowering on food safety. J Agric Food Tech 2013;3(12):1-4

23 Lombok JZ, Setiaji B, Trisunaryati W, Wijaya K. Effect of pyrolisis temperature and distillation on character of coconut shell liquid smoke. Available at: http://www.journalajst.com/sites/ default/files/1576.pdf. Accessed June 19, 2020

24 Sukharnikov IY, Esengaraev E, Turgenbaev AT, Iskakov MS. Production, properties and use of the rice hulls pyrolysis organic product as a disinfectant. World J Vet Med Eng 2015;1(1):1-8

25 Belikov AV, Schraven B, Simeoni L. T cells and reactive oxygen species. J Biomed Sci 2015;22(1):85

26 Istiati NI, Surjono I. Surboyo MDC. Role of lactoferrinin fibroblast growth factor 2 and vascular endothelial growth factor in gingival wounds. J Krishna Inst Med Sci Univ 2019;8(3):38-45

27 Suryadi IA, Asmarajaya A, Maliawan S. Proses Penyembuhan dan Penanganan Luka. Ilmu Penyakit Bedah; $2012 ; 1-19$

28 Limtrakul P, Yodkeeree S, Pitchakarn P, Punfa W. Suppression of Inflammatory Responses by Black Rice Extract in RAW 264.7 Macrophage Cells via Downregulation of NF-kB and AP-1 Signaling Pathways. Asian Pac J Cancer Prev 2015; 16(10):4277-4283

29 Friedman M. Rice brans, rice bran oils, and rice hulls: composition, food and industrial uses, and bioactivities in humans, animals, and cells. J Agric Food Chem 2013;61(45): 10626-10641

30 Luig M, Kluger MA, Goerke B, et al. Inflammation-induced IL-6 functions as a natural brake on macrophages and limits GN. J Am Soc Nephrol 2015;26(7):1597-1607
31 Choy E. Interleukin-6 as a multifunctional regulator: inflammation, immune response, and fibrosis. Cold Spring Harb Perspect Biol 2017;2(2):1-5

32 Tarawan VM, Mantilidewi KI, Dhini IM, Radhiyanti PT, Sutedja E. Coconut shell liquid smoke promotes burn wound healing. J Evid Based Complementary Altern Med 2017;22(3):436-440

33 Barrientos S, Stojadinovic O, Golinko MS, Brem H, Tomic-Canic M. Growth factors and cytokines in wound healing. Wound Repair Regen 2008;16(5):585-601

34 Gallucci RM, Sloan DK, Heck JM, Murray AR, O'Dell SJ. Interleukin 6 indirectly induces keratinocyte migration. J Invest Dermatol 2004;122(3):764-772

35 Surboyo MDC, Mahdani FY, Ernawati DS, Sarasati A, Rezkita F. The macrophage responses during diabetic oral ulcer healing by liquid coconut shell smoke: an immunohistochemical analysis. Eur J Dent 2020;1-5 DOI: 10.1055/s-0040-1712776

36 Okizaki S, Ito Y, Hosono K, et al. Suppressed recruitment of alternatively activated macrophages reduces TGF- $\beta 1$ and impairs wound healing in streptozotocin-induced diabetic mice. Biomed Pharmacother 2015;70:317-325

37 Wang L, Qin W, Zhou Y, et al. Transforming growth factorßplays an important role in enhancing wound healing by topical application of povidone-iodine. Sci Rep 2017;7(1):991

38 Liu Y, Li Y, Li N, et al. TGF- $\beta 1$ promotes scar fibroblasts proliferation and transdifferentiation via up-regulating MicroRNA-21. Sci Rep 2016;6:32231

39 Liarte S, Bernabé-García Á, Nicolás FJ. Role of TGF-ßin skin chronic wounds: a keratinocyte perspective. Cells 2020; 9(2):306

40 Surboyo MDC, Mahdani FY, Savitri DS, et al. Number of macrophages and transforming growth factorßexpression in Citrus limon L. Tlekung peel oil-treated traumatic ulcers in diabetic rats. Trop J Pharm Res 2019;18(7):1427-1433

41 Hendriati L, Hamid IS, Widodo T, Wandasari C, Risata PM. Effect of egg white gel againts burn healing on white rat (Rattus novergicus) J ILMU KEFARMASIAN Indones [Internet] 2018;16(2):231

42 Savari R, Shafiei M, Galehdari H, Kesmati M, Expression of VEGF and TGF- $\beta$ genes in skin wound healing process induced using phenytoin in male rats. Jundishapur J Heal Sci2019;1-5: 10.5812/jjhs.86041

43 Zduńska K, Dana A, Kolodziejczak A, Rotsztejn H. Antioxidant properties of ferulic acid and its possible application. Skin Pharmacol Physiol 2018;31(6):332-336 